\title{
BMJ Open Access to the NHS by telephone and Internet during an influenza pandemic: an observational study
}

\author{
Paul Rutter, ${ }^{1}$ Oliver Mytton, ${ }^{2}$ Benjamin Ellis, ${ }^{3}$ Liam Donaldson ${ }^{1}$
}

To cite: Rutter P, Mytton 0, Ellis $B$, et al. Access to the NHS by telephone and Internet during an influenza pandemic: an observational study. BMJ Open 2014;4: e004174. doi:10.1136/ bmjopen-2013-004174

- Prepublication history for this paper is available online. To view these files please visit the journal online (http://dx.doi.org/10.1136/ bmjopen-2013-004174).

Received 4 October 2013 Revised 23 December 2013 Accepted 10 January 2014

CrossMark

\footnotetext{
${ }^{1}$ Imperial College London, London, UK

${ }^{2}$ Department of Public Health, University of Oxford, Oxford, UK

${ }^{3}$ School of Clinical Medicine, University of Cambridge, Cambridge, UK
}

Correspondence to Dr Paul Rutter; paul.rutter09@imperial.ac.uk

\section{ABSTRACT}

Objectives: To examine use of a novel telephone and Internet service-the National Pandemic Flu Service (NPFS) - by the population of England during the 2009-2010 influenza pandemic.

Setting: National telephone and Internet-based service.

Participants: Service available to population of England ( $n=51.8$ million).

Primary and secondary outcome measures:

Primary: service use rate, by week. Numbers and agespecific and sex-specific rates of population who: accessed service; were authorised to collect antiviral medication; collected antiviral medication; were advised to seek further face-to-face assessment. Secondary: daily mean contacts by hour; proportion using service by telephone/Internet.

Results: The NPFS was activated on 23 July 2009, operated for 204 days and assessed 2.7 million patients (5200 consultations/100 000 population). This was six times the number of people who consulted their general practitioner with influenza-like illness during the same period (823 consultations/100 000 population, rate ratio $(\mathrm{RR})=6.30,95 \% \mathrm{Cl} 6.28$ to 6.32$)$. Women used the service more than men (52.6 vs 43.4 assessments/1000 population, RR1 21, 95\% Cl 1.21 to 1.22). Among adults, use of the service declined with age (16-29 years: 74.4 vs 65 years+: 9.9 assessments/1000 population (RR 7.46 95\% Cl 7.41 to 7.52). Almost three-quarters of those assessed met the criteria to receive antiviral medication (1 807 866/ $2488510 ; 72.6 \%$ ). Most of the people subsequently collected this medication, although more than onethird did not ( $n=646709 ; 35.8 \%)$. Just over one-third of those assessed were advised to seek further face-toface assessment with a practitioner (951 332/ 2488 504; 38.2\%).

Conclusions: This innovative healthcare service operated at large scale and achieved its aim of relieving considerable pressure from mainstream health services, while providing appropriate initial assessment and management for patients. This offers proof-of-concept for such a service that, with further refinement, England can use in future pandemics. Other countries may wish to adopt a similar system as part of their pandemic emergency planning.
Strengths and limitations of this study

- Complete data ascertainment from the 2.7 million people who used the National Pandemic Flu Service.

- Data were self-reported, without clinical validation or follow-up.

- Comparisons with GP consultation data illustrate how healthcare-seeking behaviour during the pandemic differed by age and sex.

\section{INTRODUCTION}

England started planning for the emergence of a new influenza virus with pandemic potential following a warning by the Chief Medical Officer in 2002 about the risks of being unprepared. ${ }^{1}$ The plan foresaw that widespread infection would cause a surge in demand for primary care and hospital services that could quickly overwhelm them. Planning, therefore, focused on a new way of providing first response to patients with influenza-like illness (ILI) during a pandemic. The concept involved telephone call centres and the Internet and evaluation of symptoms, provision of advice and authorisation of antiviral medication in appropriate clinical circumstances. This was to be the first time in the UK that patients would be assessed and given a prescription medication without being seen by a doctor or nurse. ${ }^{2}$ The system was intended to keep general practitioners free to see patients who developed serious illness as a result of influenza infection, but to continue also managing their normal caseload.

On 11 June 2009, the WHO formally declared the first influenza pandemic for 40 years. $^{3}$ The virus had first emerged in Mexico in March 2009. By May of that year it had spread worldwide. The first case in the UK occurred in Scotland in late April, and was followed shortly by the first cases in England. ${ }^{5}$ The UK response was characterised by two phases-an initial 
containment response from May to June 2009 and a subsequent mitigation (or 'treatment-only') phase. ${ }^{6}$ The containment phase involved a proactive response, with the aim of limiting and delaying the virus' spread. It included school closures, early treatment of suspected cases based on clinical criteria and contact tracing to provide prophylaxis to close contacts of cases. The incidence of influenza began to rise in mid-June. By July 2009, ILI was putting great pressure on the country's National Health Service (NHS), particularly general practice (GP), which in England provides the majority of front-line primary care. In response, the government activated its emergency plan to establish this national telephone and Internet-based service.

We report on the experience with this novel service for assessment and treatment of pandemic influenza, and the way that it was used by the public.

\section{CONTEXT: THE NATIONAL PANDEMIC FLU SERVICE}

The service, first activated on 23 July 2009 during the mitigation phase of the public health response, was named the National Pandemic Flu Service (NPFS). Any member of the public with 'flu-like' symptoms could access it by telephone or on the Internet (Internet users answering a series of questions on-screen). Telephone users were asked the same questions by a call centre operative.

Each assessment consisted of a set of yes/no questions. Via a standard algorithm, the responses to these questions determined the advice given to each patient and whether or not a course of antiviral medication was authorised for the patient. Each patient passed through an assessment of up to three stages (see figure 1).

The first stage was a preassessment screen, to redirect patients in need of urgent personal medical attention. Patients reporting features such as unconsciousness, seizures or meningococcal-like rash were told to call an emergency ambulance rather than continue using the service. Patients who had recently returned from a malarial region were directed to see their general practitioner urgently instead of using the service, as were all children under 1 year and pregnant women with a history of respiratory disease. All other patients entered the second stage of the assessment.

The second stage identified whether the patient had the classic symptoms of influenza. The question asked was: "Does the patient have a high temperature and at least two of the following symptoms?-Widespread muscle and joint aches, a cough, headache, blocked or runny nose, sore throat, vomiting, watery diarrhea, cannot stop crying (only children)". Those who answered 'yes' progressed to the third stage of the assessment. The remainder were informed that they were unlikely to have influenza and their contact with the service ended, with advice being given.

Patients arriving at the third assessment stage were, therefore, those identified as having ILI. In this third stage, further information was collected on four factors: how long they had been symptomatic; whether antivirals had already been taken; risk factors predisposing to severe illness (such as chronic lung disease and immunocompromise) and symptoms suggestive of severe illness (cough productive of yellow, green, brown or bloody phlegm; uncharacteristic behaviour change; pleuritic chest pain; respiratory distress; drowsiness). Those who had been ill for more than a week were also asked whether they had non-'flu-like' symptoms of acute illness (eg, persistent vomiting or severe earache).

The answers given in the third stage determined whether or not the patient was given an authorisation number to obtain a course of antiviral medication. The answers also determined what advice was given to the patient, including whether or not they were also advised to contact another healthcare service-usually their general practitioner, but sometimes a midwife (if pregnant) or a renal specialist (those with pre-existing renal disease).

A network of antiviral distribution centres was established around England, in locations such as community centres, sports centres and pharmacies. Any assessed patient who required antiviral medication was asked to find a 'flu friend' (a relative, friend or neighbour) to collect this on their behalf from a distribution centre, using the authorisation number provided by the service. Collection by a third party was intended to reduce the spread of infection at crowded distribution points.

The algorithm had been developed as part of pandemic planning, and was refined when clinical information about the influenza A (H1N1) pdm09 virus was available. The algorithm was developed and refined by a group involving clinical experts from a range of organisations, including the Health Protection Agency and the Royal College of General Practitioners (RCGP), based on their clinical experience and review of the available evidence. Legally classified as a 'medical device', the algorithm underwent fast-track regulatory approval by the Medicines and Healthcare Regulatory Authority. The Department of Health commissioned the RCGP to assure the quality of the system. General practitioner liaison advisers, coordinated by the RCGP, were based in the service's call centres.

Throughout the service's operation, the algorithm was kept under review by the clinical subgroup of the Department of Health's Pandemic Influenza Clinical and Operational Group. Refinements to the algorithm were introduced to improve safety and to minimise disruption to other services. These refinements were made based on the service's evolving experience and emerging information about the pandemic. During the service's operation, the Department of Health monitored reports of clinical incidents from a number of sources including the National Patient Safety Agency (NPSA); the call centre-based GP advisers; Strategic Health Authority and Primary Care Trust Flu Leads; the Health Protection Agency; clinical networks; and the public. 
Stage 1

Pre-assessment screen

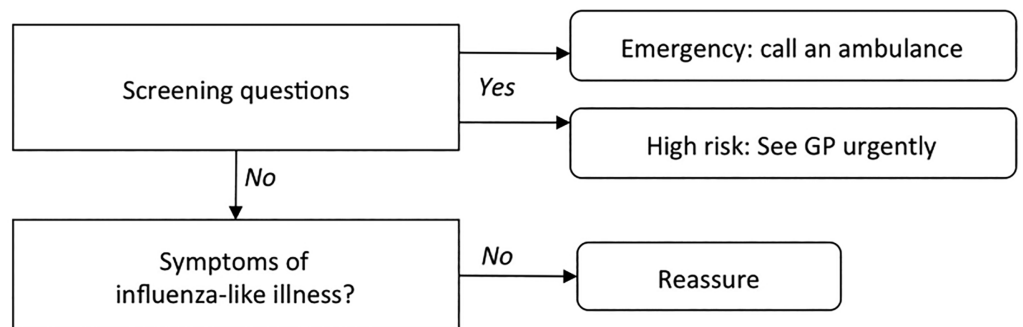

Symptom review

Yes

Stage 3

Additional information
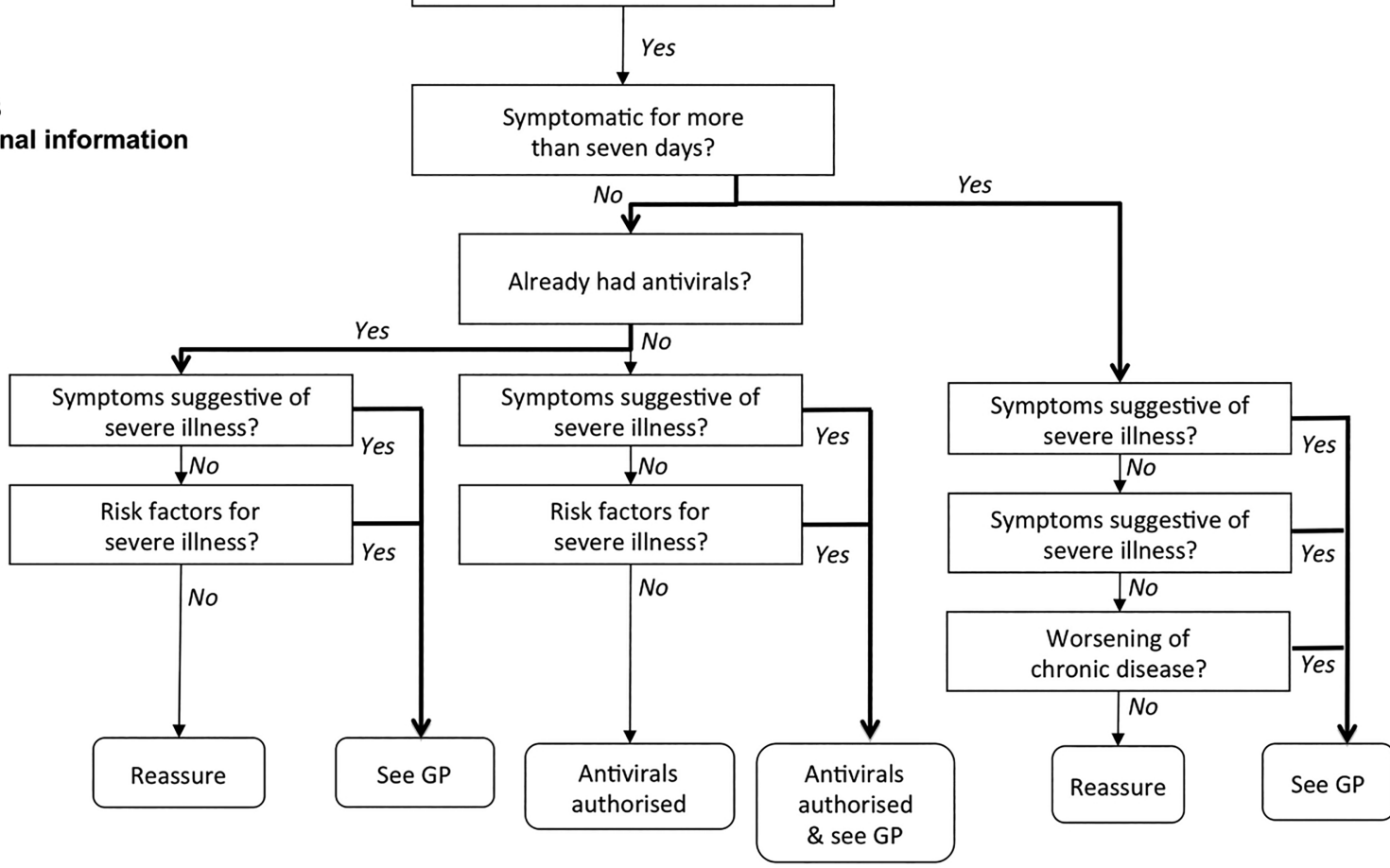

Figure 1 Algorithm for telephone/Internet-based assessment.

The decision to activate the service was taken on the basis of rising rates of ILI, coupled with information provided through close liaison with local public health officials, who were monitoring the pressure being experienced by primary care services in each area of the country. The decision to deactivate the service was taken when ILI rates were approaching background levels, and use of the service had diminished very substantially.

\section{METHODS}

Data from the telephone and Internet arms of the service were captured on a single database. For every patient who accessed the service, this recorded the date and time of accessing the service; basic demographic information (date of birth, sex); responses to each question and, therefore, the outputs of the algorithm. These data provided surveillance information during the pandemic in real time. Every collection of a course of antiviral medication was also recorded.

For comparison purposes, we also obtained data about GP consultations for ILI. The RCGP has undertaken ILI surveillance in GP for over 40 years. The system uses around 100 sentinel GPs across England, covering a population of approximately 800000 . It extracts summary information (based on Read codes ${ }^{7}$ ) from GP electronic records. This is used to estimate the rate of ILI consultations in the population of England as a whole. ${ }^{8}$ These estimates, by week of consultation, were supplied by the RCGP Research and Surveillance Centre. Based on these estimated rates, we estimated the number of GP ILI consultations in the whole of England by week and compared this to the number of NPFS consultations by week.

Population sizes by age group were obtained from the Office for National Statistics estimates for mid-2009. ${ }^{9}$ Comparisons between groups were made using two-sided $t$ tests. The Exact method was used to calculate $95 \%$ CIs for rate ratios (RR). Data were analysed in Excel 2011 and STATA V.12.1.

This analysis was part of an enhanced public health surveillance programme during the pandemic. No explicit ethical approval was required for data collection because it had a statutory basis under the Health Service (Control of Patient Information) Regulations SI1438/2002.

\section{RESULTS}

The NPFS was activated across England on 23 July 2009. It remained operational for 204 days, until 10 February 


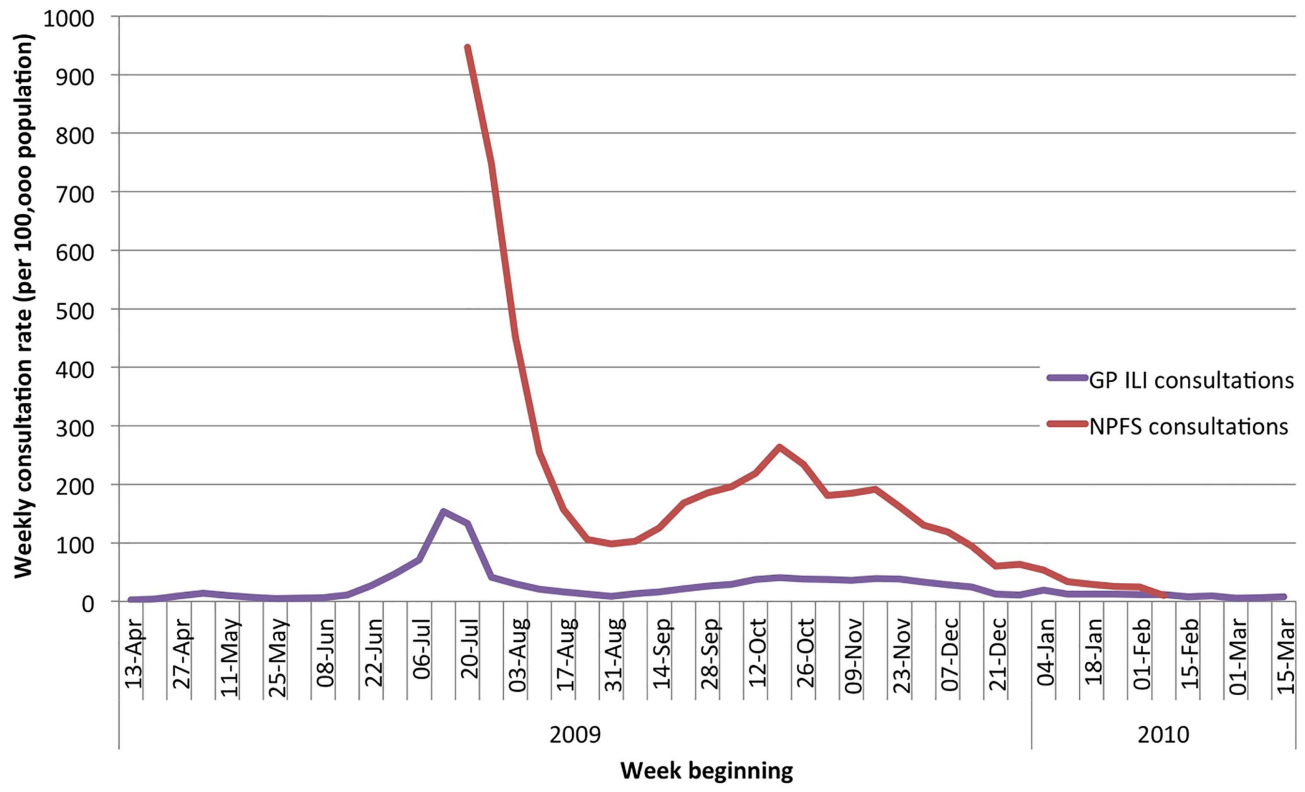

Figure 2 Weekly rates of general practice (GP) consultations with influenza-like illness and National Pandemic Flu Service consultations, by week, in England, April 2009-February 2010.

2010. During this time, it received 2.73 million unique patient contacts (5200 contacts/100 000 population).

Contacts occurred in two clear waves (figure 2). The first was short, covering June and July 2009. The second was more prolonged between September and December 2009. The rate of NPFS contacts at the peak of the first wave was more than three times higher than in the second wave (135 vs 38 consultations/100 000 population/day, RR $3.59,95 \%$ CI 3.53 to 3.65 ).

Over the same period, there were just 429000 GP consultations related to ILI in England (827 consultations/ 100000 population). These also occurred in two waves (figure 2). NPFS contacts exceeded GP consultations by a factor of almost six ( $R R=5.76,95 \%$ CI 5.72 to 5.80$)$. The difference was most marked in the service's second week of operation (748 vs 41.1 consultations/100 000 population/week, $\mathrm{RR}=18.2$, 95\% CI 17.6 to 18.9 ) and subsequently diminished over time.

The number of GP consultations related to influenzalike illness had been rising sharply in June and early July 2009, before the NPFS was activated. In the week beginning, 13 July 2009, there were 154 GP consultations/ 100000 population/week (80000 consultations in total). During the subsequent week, the NPFS was activated and

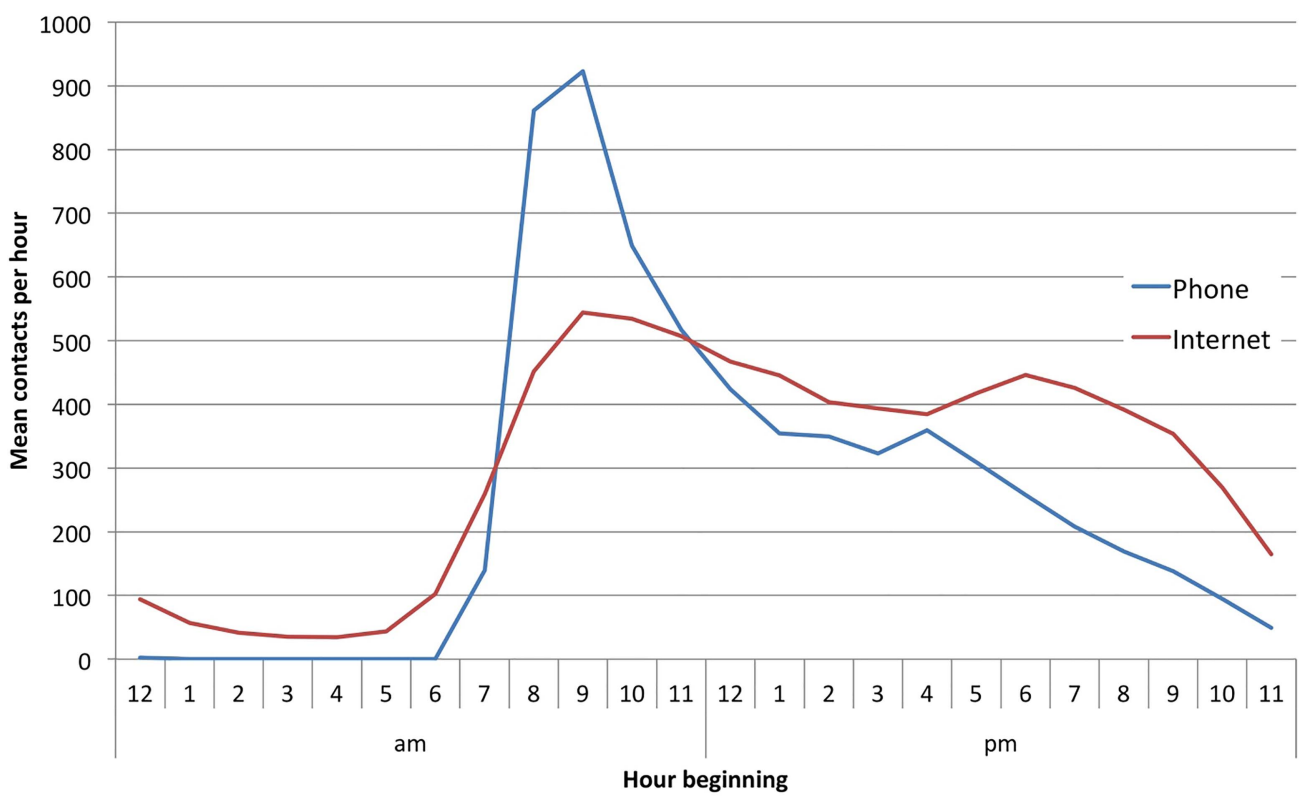

Figure 3 Daily mean contacts per hour to each arm of the National Pandemic Flu Service. 
the number of GP consultations fell to $133 / 100000$ people/week (69 000 consultations in total).

Just over half of patients (1 $305902 / 2488504 ; 53 \%$ ) used the Internet service arm; the remainder used the telephone. Each method had distinct daily usage patterns (figure 3). Usage of both peaked between 9:00 and 10:00. Just under one-quarter (22\%; 279 150/1 250 184) of telephone contacts happened at other times. Usage of the Internet-based service was more evenly spread throughout the day. Just under half of its usage was outside ' $9-5$ ' h $(43 \%, 639684 / 1482404)$. In total, an average of 13500 assessments were completed per day. The mean daily volume of assessments was higher during the week than at the weekend (14600 vs 10600 , $\mathrm{p}<0.0001)$.

Of the 2.73 million contacts with the NPFS, 9\% ( $\mathrm{n}=244078$, figure 4) were immediately diverted because they related to a child aged under 1 year, a pregnant woman with respiratory disease or because the patient described features of a potential medical emergency. The remaining patients entered the full assessment process. Almost three-quarters of these (1 $807866 / 2488510$; 73\%) received authorisation to collect a course of antiviral medication. Most did subsequently collect this, although a substantial minority did not $(\mathrm{n}=646709 ; 36 \%)$.

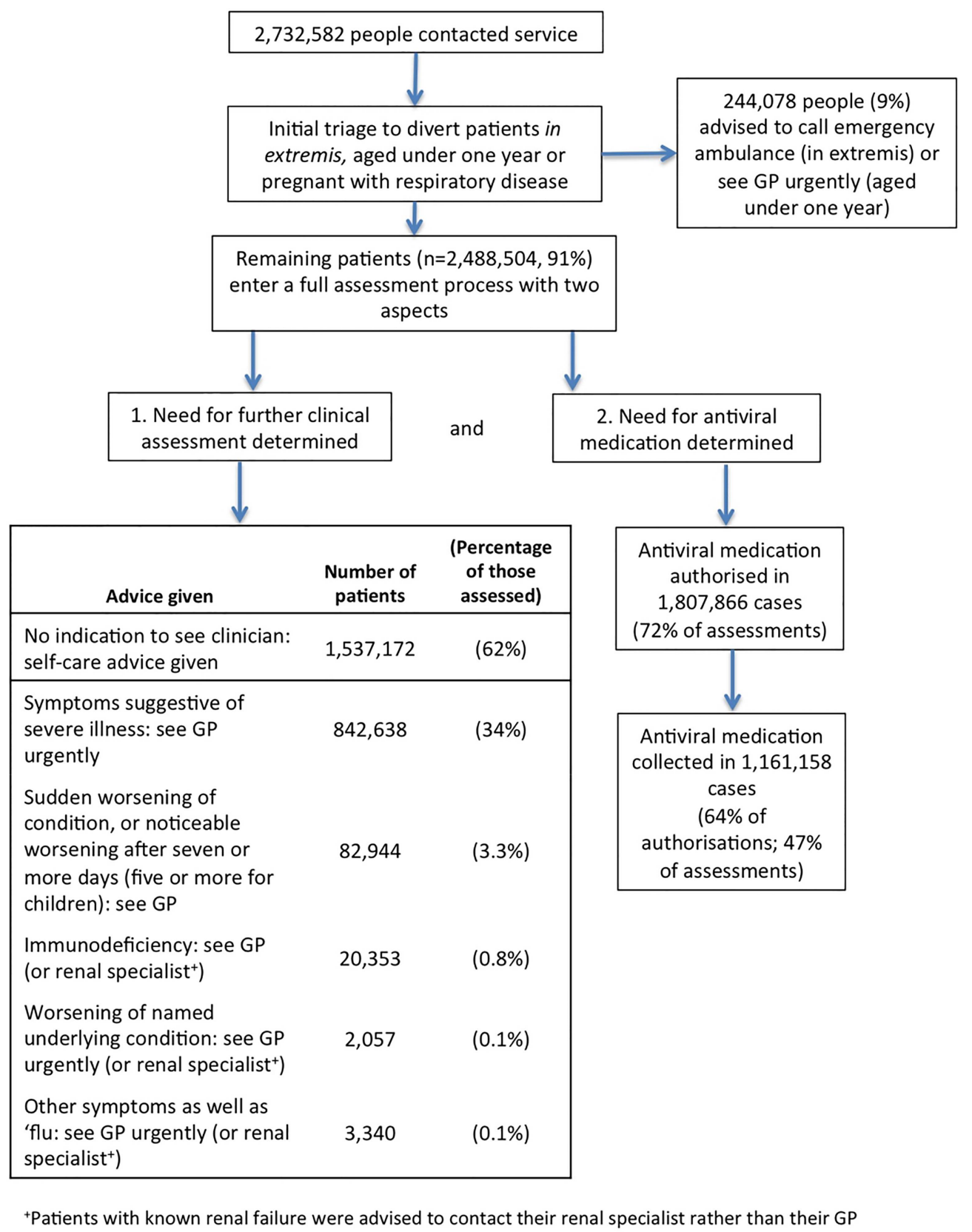

Figure 4 Patient assessment by the National Pandemic Flu Service (204 days, July 2009-February 2010). 
The algorithm determined that almost two-thirds of patients $(\mathrm{n}=1537178 ; 62 \%)$ did not require further assessment by a clinician. These patients received selfcare advice. The remainder were advised to seek in-person medical assessment $(n=951332 ; 38 \%)$, the form of which depended on its indication (figure 4).

Use of the NPFS varied demographically (table 1 ). Women used it more than men (52.6 vs 43.4 assessments/1000 population, RR $1.21,95 \%$ CI 1.21 to 1.22 ), but men appeared to show a greater preference than women for the NPFS relative to visiting their GP (ratio of NPFS:RCGP 6.1 for men vs 5.6 for women, table 2). Use declined with age: the assessment rate was seven times greater among 16-29-year-olds than among the over-65s (74.4 vs 9.9 assessments/1000 population, RR $7.46,95 \%$ CI 7.41 to 7.52 ). Preferential use of the NPFS rather than GP was particularly high among the young and middle-aged (table 2).

Men were offered antiviral medication slightly more often than women $(74 \%$ for men vs $72 \%$ for women, $\left.\chi^{2}=1812, \mathrm{p}<0.0001\right)$. Antiviral medication authorisations were highest for the age group between 1 and 15 years $(78 \%$, table 1$)$, generally reduced with age $\left(\chi^{2}=6.1 \times 10^{5}\right.$, $\mathrm{p}<0.0001)$ and were lowest for the over-65s $(59 \%)$.

Of those eligible to collect a course of antiviral medication, just under two-thirds did so (1 161 156/1 807 $866 ; 64 \%)$. Those aged $16-29$ years were the least likely to collect their medication $(317155 / 528211 ; 60 \%)$ and those aged 65 years and over the most likely (36 182/ 49 152; 74\%). When a child aged between 1 and 15 years was deemed eligible for antiviral medication, this medication was collected in $64 \%$ of cases.

Men were slightly more likely than women to access the service via the Internet rather than telephone $(53 \%$ vs $\left.52 \%, \chi^{2}=288.61, \mathrm{p}<0.0001\right)$ but variation between age groups was greater (figure 5). Young adults were more likely to opt for Internet-based access (25-44 years, $59 \%$ ) and the oldest group least likely to do so (75 years and over, 28\%, RR $2.195 \%$ CI 2.0 to 2.1 ).

\section{DISCUSSION}

The National Pandemic Flu Service was designed, in advance of the pandemic, to prevent the NHS being overwhelmed by people seeking medical advice and treatment of 'flu-like' symptoms due to heightened public awareness and concern. By providing antiviral medication to 'flu friends' at distribution centres, it was intended to enable the sick to stay at home and thereby reduce the spread of infection. It was planned to quickly provide antiviral medication to those who might benefit from it.

When the pandemic came and this new service was activated, the population proved very willing to use it. The service dealt with a high volume of contacts, assessing 2.7 million patients in less than 7 months. It distributed antiviral medication to over one million people. We suggest that its activation and use in the 2009-2010 pandemic provides successful proof-of-concept for this approach.

A strength of this article is that it uses data on all patients who accessed the service. A weakness, because of the nature of the service, is that the information was reported by patients and was not clinically validated. Apart from the incident reporting systems described later, there are no patient follow-up data to assess outcomes or confirm underlying diagnoses. Results of microbiological sampling of patients who used the service have been published elsewhere. ${ }^{6}$ Also, our estimates for GP consultations are based on the RCGP sentinel surveillance system. Owing to the nature of sampling this may not accurately reflect the true picture across England.

\begin{tabular}{|c|c|c|c|c|c|c|c|}
\hline & $\begin{array}{l}\text { Population } \\
\text { (thousands) }\end{array}$ & $\begin{array}{l}\text { Assessments } \\
\text { (thousands) }\end{array}$ & $\begin{array}{l}\text { Courses of } \\
\text { antiviral } \\
\text { medication } \\
\text { authorised } \\
\text { (thousands) }\end{array}$ & $\begin{array}{l}\text { Courses of } \\
\text { antiviral } \\
\text { medication } \\
\text { collected } \\
\text { (thousands) }\end{array}$ & $\begin{array}{l}\text { NPFS } \\
\text { assessment } \\
\text { rate } \\
\text { (assessments/ } \\
1000 \\
\text { population }\end{array}$ & $\begin{array}{l}\text { Authorised } \\
\text { to receive } \\
\text { antiviral } \\
\text { medication } \\
\text { (\%) }\end{array}$ & $\begin{array}{l}\text { Collected } \\
\text { antiviral } \\
\text { medication } \\
\text { once } \\
\text { authorised } \\
(\%)\end{array}$ \\
\hline All & 51810 & 2489 & 1808 & 1161 & 48.0 & 73 & 64 \\
\hline \multicolumn{8}{|l|}{ Sex } \\
\hline Male & 25515 & 1106 & 819 & 529 & 43.4 & 74 & 65 \\
\hline Female & 26295 & 1382 & 989 & 632 & 52.6 & 72 & 64 \\
\hline \multicolumn{8}{|l|}{ Age (years) } \\
\hline $1-15$ & 9041 & 637 & 495 & 318 & 70.4 & 78 & 64 \\
\hline $16-29$ & 9749 & 725 & 528 & 317 & 74.4 & 73 & 60 \\
\hline $30-44$ & 10874 & 621 & 437 & 281 & 57.1 & 70 & 64 \\
\hline $45-59$ & 9941 & 356 & 255 & 177 & 35.8 & 71 & 70 \\
\hline $60-64$ & 3107 & 65 & 43.2 & 31.6 & 21.0 & 66 & 73 \\
\hline 65 and over & 8435 & 84 & 49.2 & 36.2 & 9.9 & 59 & 74 \\
\hline
\end{tabular}


Table 2 Comparison of GP consultation and NPFS assessment rates

\begin{tabular}{|c|c|c|c|c|c|c|}
\hline & $\begin{array}{l}\text { Population } \\
\text { (thousands) }\end{array}$ & $\begin{array}{l}\text { GP } \\
\text { consultation } \\
\text { rate (per } \\
\text { thousand) }\end{array}$ & $\begin{array}{l}\text { NPFS } \\
\text { assessment } \\
\text { rate (per } \\
\text { thousand) }\end{array}$ & $\begin{array}{l}\text { GP } \\
\text { consultations } \\
\text { (thousands) } \\
\end{array}$ & $\begin{array}{l}\text { NPFS } \\
\text { assessments } \\
\text { (thousands) } \\
\end{array}$ & $\begin{array}{l}\text { Ratio of NPFS } \\
\text { assessments to GP } \\
\text { consultations }\end{array}$ \\
\hline All & 51810 & 8.3 & 48.0 & 429 & 2489 & 5.8 \\
\hline \multicolumn{7}{|l|}{ Sex } \\
\hline Male & 25515 & 7.1 & 43.4 & 181 & 1106 & 6.1 \\
\hline Female & 26295 & 9.4 & 52.6 & 247 & 1382 & 5.6 \\
\hline \multicolumn{7}{|l|}{ Age (years) } \\
\hline $0-14$ & 9076 & 11.4 & & 104 & & \\
\hline$(1-15)$ & 9041 & & 70.4 & & 637 & 6.1 \\
\hline $15-44$ & 21252 & 10.3 & & 218 & & \\
\hline$(16-44)$ & 20623 & & 65.3 & & 1346 & 6.2 \\
\hline $45-64$ & 13048 & 6.5 & 32.3 & 84 & 421 & 5.0 \\
\hline 65 and over & 8435 & 3.4 & 9.9 & 28 & 84 & 3.0 \\
\hline
\end{tabular}

\section{SERVICE OPERATION}

The cost of developing and maintaining the NPFS was the main infrastructure-related expenditure associated with the country's pandemic preparedness and response. The total cost of infrastructure in the UK (including some non-NPFS costs) was $£ 27.7$ million during the preparedness phase and $£ 65.7$ million during the response phase. $^{4}$

Although the telephone service was established at relatively short notice, a great deal of planning had occurred during an extended prepandemic period. The government contracted with an existing telephone triage service that was experienced in training temporary staff to use health-related algorithms and was able to scale service provision up and down according to demand.

The UK had a regular direct telephone and email service for health consultations called NHS Direct. The telephone service handled around five million calls each year and around five million people used the online symptom checker. Prior to the opening of the NPFS, some patients were contacting NHS Direct. ${ }^{6}{ }^{10}$ The proportion of calls to NHS Direct that were triaged using the cold/flu algorithm rose steadily during June and July, matching the rise in general practitioner consultations. Outside the 'flu season' the proportion is typically less than $2 \%$. This proportion peaked at $35 \%$ on $14 \mathrm{July}$, likely equivalent to around 4000-6000 daily calls (or 812 calls/100 000). This is substantially lower than peak NPFS usage when it first opened (over 130 assessments/ $100000 /$ day, around half of which were by phone). The greater propensity to contact the NPFS may be because of its ability to provide access to antiviral medication (which NHS Direct was not), or because it was specifically advertised in relation to the pandemic.

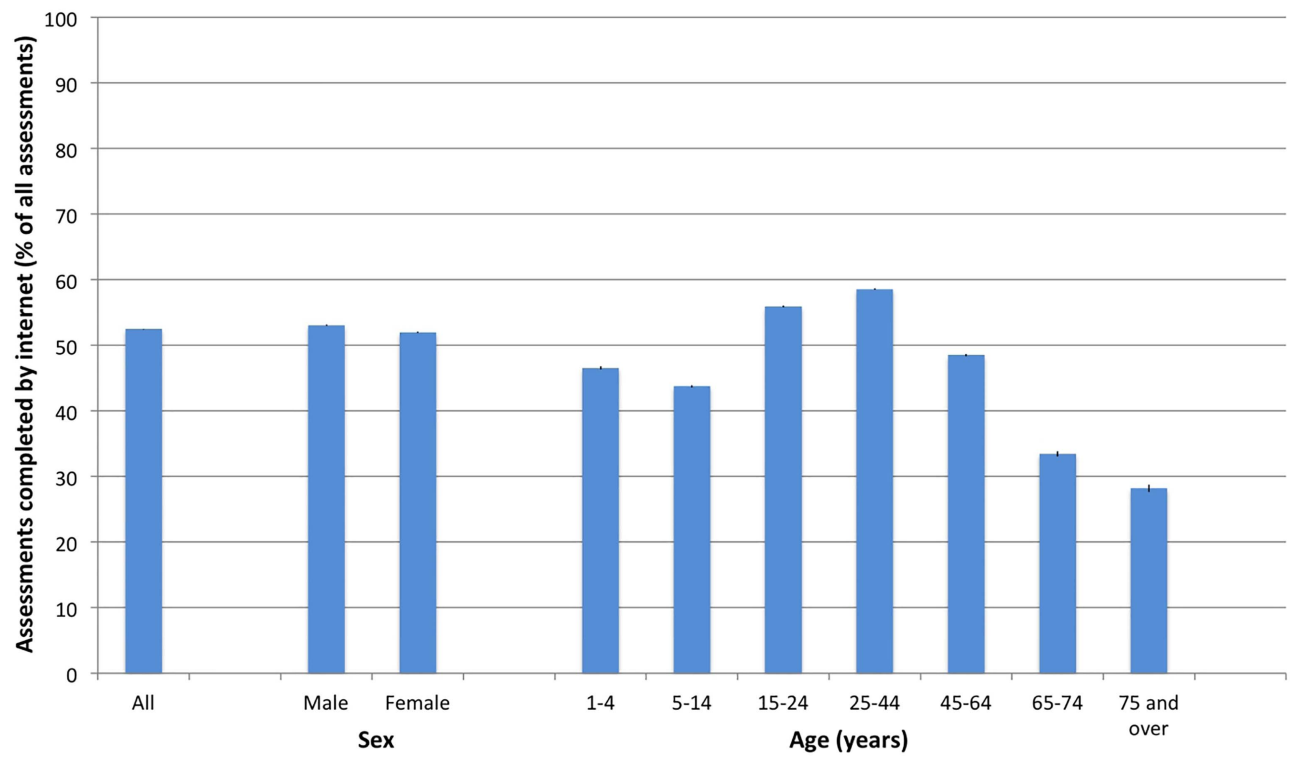

Figure 5 Use of the Internet-based arm of the National Pandemic Flu Service as a percentage of Internet-based and telephone-based use, by population group. 


\section{IMPACT ON PRIMARY CARE WORKLOAD}

The NPFS was activated after the GP consultation rate for ILI had risen for 7 weeks, and had doubled over the previous week. The weekly rate had risen to over 150 consultations/100 000 population. Although not as high as in previous influenza pandemics, this was the highest level experienced in England in a decade of 'flu seasons'. Moreover, the consultation rate was 5-10-fold higher than the national average in some areas of the country, ${ }^{6}$ causing huge pressure on primary care services in some areas.

The GP consultation rate fell in the week that the NPFS was activated (week beginning 20 July 2009), and again in its second week. We cannot conclusively attribute this to the introduction of the NPFS. Other measures suggest that influenza activity may have peaked at around the same time: hospital admissions (week beginning 20 July), critical care admissions (week beginning 27 July), deaths (week beginning 27 July) and Google searches for influenza (week beginning 27 July). ${ }^{11}$ However, the fall in GP consultations was far more pronounced than the fall in these other measures. The clear impression from general practitioners is that the service played an important role in reducing pressure on GP at a very busy time. ${ }^{412}$

\section{COMPARISON WITH OTHER UK COUNTRIES}

Wales, Scotland and Northern Ireland chose not to be part of the NPFS. Comparisons with these countries may give an insight into the effect of the NPFS in reducing GP consultations. While there are important geographical differences between the countries their health systems, although separate, are broadly comparable.

Wales and Northern Ireland had a similar experience to England. Wales had a summer peak (92.8 consultations/ 100000 population) in the same week as England (week beginning 20 July), followed by a sustained second wave in the autumn (peaking at 66.2 consultations/ 100000 in the week beginning 12 October). ${ }^{6}$ In terms of GP consultations, the ratio between the summer and autumn peaks was 1.4 in Wales compared with 3.8 in England. This may suggest that the NPFS succeeded, in England, in reducing GP consultations during the second wave.

Northern Ireland also experienced two waves. The peak of the first wave was later than in England and Wales (week beginning 27 July). Unlike in England and Wales, the second wave had a higher peak than the first wave. This too might suggest that the NPFS in England played a role in keeping GP consultations low in the second wave. Wales is arguably a better epidemiological comparator than Northern Ireland, because Wales and England adjoin whereas Northern Ireland and England are on separate islands.

The Scottish experience was very different. In Scotland, there was no summer peak in GP consultations. As in the other UK countries, there was a sustained autumn wave that peaked in October. The absence of a summer peak in Scotland may partly be explained by the earlier closure of the schools for summer holidays. ${ }^{6}$ Because the trajectory of the 'flu' pandemic appeared very different in Scotland, it is not appropriate to make comparisons with England.

Differences between the four nations in the pressure created by the pandemic were apparent from an early stage. In England, there was marked pressure on primary care, particularly in London and the West Midlands. By contrast, the pressure on primary care in Wales, Scotland and Northern Ireland was less intense. It was for these reasons that England chose to use the NPFS, while the other nations continued to rely purely on their usual primary care systems. ${ }^{4}$

\section{TELEPHONE AND INTERNET USE IN THE NHS}

In the UK, most households have Internet access, and more than two-thirds seek health information online. ${ }^{13}$ Telephone consultations have been available throughout England since the launch of NHS Direct in 1998. Staffed by nurses and health advisors, this system handled over four million calls per year, and its website received 10 million hits. NHS Direct was shown to reduce demand on out-of-hours GP services. ${ }^{14}$ Its scale and electronic medical records also made it useful for surveillance, ${ }^{15} 16$ including influenza surveillance. ${ }^{17}{ }^{18}$ Subsequently, in 2013, NHS Direct was replaced by NHS 111, another telephone and Internet-based service.

The NPFS was launched to a public that has become increasingly familiar with seeking medical help and information by phone and through Internet, as it does in many other aspects of life. But the NPFS was the first system in England-and, to our knowledge, the first national system in the world-in which non-medically trained lay people acted as the primary interface with patients, working to a standard algorithm and providing a drug that normally requires medical prescription, as deemed appropriate.

\section{THE RISKS OF ALGORITHMI-BASED CARE}

During the service's operation, concerns were raised about the possibility of misdiagnoses, particularly that led to serious illness being missed. ${ }^{19} 20$ The number of such incidents that were reported was small. The NPSA was informed of 72 incidents. By comparison, it was informed of 2410 incidents pertaining to pandemic-related healthcare as a whole. The Agency reviewed the most serious 186 of these 2410 incidents in detail. Only one serious incident was found to be related to a delay in diagnosis following use of the NPFS-that is one patient in 2.7 million who accessed the service. Diagnostic error, including delayed diagnosis, is a common problem within conventional systems of assessment and management. ${ }^{21} 22$

The RCGP concluded that "the first mass application of non-clinical-based triage appears to have been a qualified success story", and recommended amendments for future pandemics, based on the 2009 experience. ${ }^{23}$ A Department of Health evaluation set out specific 
details of problems encountered, and also laid out modifications to planned NPFS use in future pandemic plans. $^{24}$

\section{PATTERNS OF USAGE}

The highest NPFS usage rate was seen among those aged 16-29 years. The rate then decreased with age, and was also lower among children. The decrease with age among adults is consistent with the pattern of GP consultations and hospital admissions. ${ }^{11}$ However, the magnitude of this relationship was greater for the NPFS than it was for GP. The NPFS usage rate fell by a factor of five between the ages of 44 and 65 years. The GP consultation rate fell by a factor of 3 . This suggests that younger people preferred newer, more immediate ways of accessing the NHS while older people preferred the familiarity of their general practitioner. It may also be because older people have comorbid conditions, and therefore felt that they needed a face-to-face consultation with a doctor. The preferential use of the NPFS by young and middle-aged people may suggest that the system has value as a surveillance tool in those age groups.

The relatively low NPFS usage rate for children despite the high incidence of influenza among children ${ }^{6}$ may reflect a lack of awareness that parents could use the NPFS on behalf of their children or a parental preference to access usual medical care for their children.

One-third of those authorised to receive antiviral drugs through the NPFS did not subsequently collect this prescription. Collection rates for drugs prescribed by a general practitioner in England are far higher than this $(97 \%$ of drugs prescribed for infections are collected ${ }^{25}$ ), although other authors have also shown that around $30-50 \%$ of patients with a long-term condition are non-compliant with medication. ${ }^{26}$ However, in the case of the NPFS it is perhaps inevitable that a proportion of users of the service chose found that a selflimiting illness was running its course and so did not follow through with treatment.

There is a notable difference between the number of people who were advised by the NPFS to seek further medical attention and the number of people who did so. The service advised 1.2 million people to see their general practitioner. As we have reported elsewhere, ${ }^{11}$ there were a total of $580000 \mathrm{GP}$ consultations relating to ILI during the pandemic. Although some patients may have attended hospital emergency departments, this strongly suggests that a large number of the 1.2 million patients advised to seek further medical attention did not do so. Further research is required to understand the full scale of this, the reasons for this and the implications of it.

\section{WIDESPREAD USE OF ANTIVIRAL MEDICATION}

The NPFS made antiviral medication available to a large number of people with ILI, without the need to consult a medical practitioner. The number of such prescriptions made through the NPFS (1 161 157) dwarfed the number dispensed by community pharmacists on the prescription of a general practitioner (10 610 from June 2009 to February 2010). ${ }^{11}$ It seems unlikely that such high availability of prescription antiviral medication could have been achieved using the general practitioner system alone without this causing very severe disruption.

Criticism of heavy use of antiviral medication centres on concerns about antiviral resistance from their 'unnecessary' use in what was perceived as a relatively mild influenza syndrome. While a small number (45) of antiviral-resistant cases were reported,${ }^{6}$ there was no evidence of sustained person-to-person transmission of antiviral-resistant strains in the UK despite extensive testing and monitoring. ${ }^{27}{ }^{28}$ And while it is correct that case fatality rates were lower than in previous influenza pandemics, ${ }^{29}$ there were many cases of severe illness requiring intensive care ${ }^{30}$ and 70 children in England died. ${ }^{31}$

It has also been noted that the positivity rate among those authorised to collect antivirals by the NPFS were just over $30 \%$ in adults and just over $50 \%$ in children (although children were only sampled after the peak of the second wave). However, these rates were very similar (after age-adjustment) to the positivity rates among GP ILI consultations. ${ }^{6}$ In addition, the NPFS sampling scheme relied on nasal swabs taken by the patient without clinical supervision, rather than sputum or nasopharyngeal aspirates which have higher positivity rates. ${ }^{32}$ The stated NPFS positivity rates may, therefore, underestimate the true incidence of infection.

In the first pandemic of modern times when a prevaccine protective option was available in the early stages of the pandemic, we would argue that it was right to allow wide access to it, and that more deaths of young people and higher levels of serious complications were potentially prevented.

The NPFS gave patients a rapid access to antiviral medication, facilitating early use. Early use is thought to be critical for reducing illness severity and intensity in the individual. ${ }^{33}$ Also, the widespread use of antiviral medication in the community, alongside other measures, may have contributed to limiting the burden of influenza, particularly in the second wave. ${ }^{34}$ Antiviral medication may reduce transmission of the virus, ${ }^{34}$ particularly among children, ${ }^{35}$ and widespread use at a population level might reduce the overall attack rate. ${ }^{36}$ In facilitating widespread early treatment, the NPFS may have contributed to preventing adverse outcomes, such as hospitalisation, critical care admission and death. ${ }^{33} 37$

\section{CONCLUSION}

A total of 2.7 million people accessed the NPFS by telephone or Internet. They received advice and, in two-thirds of cases, authorisation to collect antiviral medication. The service seemed to appeal particularly to younger patients. Pressure on primary care fell dramatically after its 
introduction, although this cannot wholly be attributed to the service. Together with the formal evaluation and review of safety data, the experiences presented here offer evidence of the feasibility of rapid, national implementation of a telephone-based and Internet-based triage and antiviral authorisation service, based on non-clinically trained operators following defined algorithms. With further refinement, England can use this in future pandemics (which could be of much greater severity). Other countries may wish to adopt a similar system as part of their pandemic emergency planning.

Acknowledgements The authors are grateful to the RCGP Research and Surveillance Centre for the GP ILI consultation data reported in this article.

Contributors Data analysis was undertaken by $\mathrm{OM}$ and PR. The article was drafted by PR and OM and critically reviewed by BE and LD. All authors contributed to the conception and design of this work and approved the final version.

Funding This research received no specific grant from any funding agency in the public, commercial or not-for-profit sectors.

Competing interests During the influenza pandemic described, LD was Chief Medical Officer for England and PR, OM and BE were Clinical Advisers to him.

Ethics approval This analysis was part of an enhanced public health surveillance programme during the pandemic. No explicit ethical approval was required for data collection because it had a statutory basis under the Health Service (Control of Patient Information) Regulations SI1438/2002.

Provenance and peer review Not commissioned; externally peer reviewed.

Data sharing statement No additional data are available.

Open Access This is an Open Access article distributed in accordance with the Creative Commons Attribution Non Commercial (CC BY-NC 3.0) license which permits others to distribute, remix, adapt, build upon this work noncommercially, and license their derivative works on different terms, provided the original work is properly cited and the use is non-commercial. See: http:// creativecommons.org/licenses/by-nc/3.0/

\section{REFERENCES}

1. Department of Health, UK. Getting Ahead of the Curve: a strategy for infectious diseases. 2002. http://webarchive.nationalarchives.gov. uk/+/dh.gov.uk/en/consultations/closedconsultations/dh_4016942 (accessed 29 May 2013).

2. Department of Health, UK. Pandemic flu: a national framework for responding to an influenza pandemic. London, 2002. http://webarchive. nationalarchives.gov.uk/20130107105354/http://www.dh.gov.uk/en/ Publicationsandstatistics/Publications/PublicationsPolicyAndGuidance/ DH_080734 (accessed 29 May 2013).

3. Chan M. World now at the start of 2009 influenza pandemic. World Health Organization, 2009. http://www.who.int/mediacentre/news/ statements/2009/h1n1_pandemic_phase6_20090611/en/index.html (accessed 29 May 2013).

4. Hine D. An independent review of the UK response to the 2009 influenza pandemic. July 2010. http://webarchive.nationalarchives. gov.uk/+/http:/www.cabinetoffice.gov.uk/media/416533/ the2009influenzapandemic-review.pdf (accessed 29 May 2013).

5. Health Protection Agency. Suspected cases in Scotland test positive for swine influenza. 27 April 2009. http://www.hpa.org.uk/web/ HPAweb\&HPAwebStandard/HPAweb_C/1240812259242 (accessed 29 May 2013)

6. Health Protection Agency. Epidemiological report of pandemic (H1N1) 2009 in the UK; April 2009-May 2010. http://www.hpa.org.uk/webc/ HPAwebFile/HPAweb C/1284475321350 (accessed 29 May 2013).

7. National Health Service Connecting for Health (NHS CFH). Read codes. http://www.connectingforhealth.nhs.uk/systemsandservices/ data/uktc/readcodes (accessed 29 May 2013).

8. Fleming DM, Miles J. The representativeness of sentinel practice networks. J Public Health 2010;32:90-6.

9. Office for National Statistics. Population Estimates for UK, England and Wales, Scotland and Northern Ireland. London, 2009. http:// www.ons.gov.uk/ons/rel/pop-estimate/population-estimates-for-ukengland-and-wales-scotland-and-northern-ireland/2009/index.html (accessed 29 May 2013).

10. Elliot AJ, Powers C, Thornton A, et al. Monitoring the emergence of community transmission of influenza A/H1N1 2009 in England: a cross sectional opportunistic survey of self sampled telephone callers to NHS Direct. BMJ 2009;339:b3403.

11. Mytton OT, Rutter PD, Donaldson LJ. Influenza A (H1N1) pdm09 in England, 2009 to 2011: a greater burden of severe disease in the year after the pandemic than in the pandemic year. Eurosurveillance 2012;17:pii20139.

12. Caley M, Sidhu K, Shukla R. GPs' opinions on the NHS and HPA response to the first wave of the influenza $A / H 1 N 1 v$ pandemic. Br J Gen Pract 2010;60:283-5.

13. Powell J, Inglis N, Ronnie J, et al. The characteristics and motivations of online health information seekers: cross-sectional survey and qualitative interview study. $J$ Int Med Res 2011;13:e20.

14. Munro J, Sampson F, Nicholl J. The impact of NHS Direct on the demand for out-of-hours primary and emergency care. $\mathrm{Br} J \mathrm{Gen}$ Prac 2005;55:790-2.

15. Loveridge P, Cooper D, Elliot AJ, et al. Vomiting calls to NHS Direct provide an early warning of norovirus outbreaks in hospitals. J Hosp Infect 2010;74:385-93.

16. Elliot AJ, Singh N, Loveridge $P$, et al. Syndromic surveillance to assess the potential public health impact of the Icelandic volcanic ash plume across the United Kingdom. Eurosurveillance 2010;15: pii19583.

17. Cooper DL, Verlander NQ, Elliot AJ, et al. Can syndromic thresholds provide early warning of national influenza outbreaks? J Public Health 2009:31:17-25.

18. Smith S, Smith GE, Olowokure B, et al. Early spread of the 2009 infuenza $A(\mathrm{H} 1 \mathrm{~N} 1)$ pandemic in the United Kingdom-use of local syndromic data, May-August 2009. Eurosurveillance 2011;16: pii19771.

19. The Guardian. Girl, two, dies after swine flu misdiagnosis. 8 August 2009. http://www.guardian.co.uk/uk/2009/aug/08/ swine-flu-misdiagnosis-death (accessed 29 May 2013).

20. Houlhan CF, Patel S, Price DA, et al. Life threatening infections labeled swine flu (letter). BMJ 2010;340:c137.

21. Newman-Toker DE, Pronovost PJ. Diagnostic errors-the next frontier for patient safety. JAMA 2009;301:1060-2.

22. Schiff GD, Hasan O, Kim S, et al. Diagnostic error in medicine: analysis of 583 physician-reported errors. Arch Intern Med 2009;169:1881-7.

23. Royal College of General Practitioners. Quality Assuring the NPFS... and further RCGP reflections of Pandemic H1N1 (2009). A report on the NPFS and the H1N1 swine flu outbreak for the Chief Medical Officer. February 2010.

24. Department of Health. The National Pandemic Flu Service: An Evaluation. March 2011. https://www.gov.uk/government/uploads/ system/uploads/attachment data/file/147395/dh_125338.pdf (accessed 29 May 2013).

25. The Health and Social Care Information Centre. Prescribing compliance: a review of the proportion of prescriptions dispensed. September 2011. https://catalogue.ic.nhs.uk/publications/prescribing/primary/ pres-comp-rev-prop-pres-disp/pres-comp-rev-prop-pres-disp-rep.pdf (access 29 May 2013).

26. Garfield S, Clifford S, Eliasson L, et al. Suitability of measures of self-reported medication adherence for routine clinical use: a systematic review. BMC Med Res Methodol 2011;11:149.

27. Calatavud L, Lackenby A, Reynolds A, et al. Oseltamivir-resistant pandemic (H1N1) 2009 virus infection in England and Scotland, 2009-10. Emerg Infect Dis 2011;17:1807-15.

28. Lackenby A, Elliot AJ, Powers $C$, et al. Virological self-sampling to monitor influenza antiviral susceptibility in a community cohort. $J$ Antimicrob Chemo 2013;68:2324-31.

29. Donaldson LJ, Rutter PD, Ellis BM, et al. Mortality from pandemic A/H1N1 2009 influenza in England: public health surveillance study. BMJ 2009;339:b5213.

30. Campbell CN, Mytton OT, McLean EM, et al. Hospitalization in two waves of pandemic influenza $\mathrm{A}(\mathrm{H} 1 \mathrm{~N} 1)$ in England. Epidemiol Infect 2011;139:1560-9.

31. Sachedina N, Donaldson LJ. Paediatric mortality related to pandemic influenza A H1N1 infection in England: an observational population-based study. Lancet 2010;376:1846-52.

32. Gavin PJ, Thomson RB. Review of rapid diagnostic tests for influenza. Clin Appl Imm Rev 2004;4:151-72.

33. Kumar A. Early versus late oseltamivir treatment in severely ill patients with 2009 pandemic influenza $A(\mathrm{H} 1 \mathrm{~N} 1)$ : speed is life. $J$ Antimicrob Chemother 2011;66:959-63. 
34. Pebody RG, Harris R, Kafatos G, et al. Use of antiviral drugs to reduce household transmission of pandemic (H1N1) 2009, United Kingdom. Emerg Infect Dis 2011:17:990-9.

35. Wang K, Shun-Shin M, Gill P, et al. Neuraminidase inhibitors for preventing and treating influenza in children. Cochrane Database Syst Rev 2012;1:CD002744.
36. Halder N, Kelso JK, Milne GJ. Analysis of the effectiveness of interventions used during the $2009 \mathrm{~A} / \mathrm{H} 1 \mathrm{~N} 1$ influenza pandemic. BMC Pub Health 2010;10:168.

37. Hsu J, Santesso N, Mustafa R, et al. Antivirals for Treatment of Influenza: a systematic review and meta-analysis of observational studies. Ann Intern Med 2012;156:512-24. 